\title{
Changes in regional grain yield responses to chemical fertilizer use in China over the last 20 years
}

\author{
Xiaobin Wang ${ }^{1 *}$, Dianxiong Cai ${ }^{1 *}$, Cynthia Grant ${ }^{2}$, Willem B Hoogmoed ${ }^{3}$, Oene Oenema ${ }^{4}$
}

${ }^{1}$ Institute of Agricultural Resources and Regional Planning, Chinese Academy of Agricultural Sciences, Beijing 100081, China. ${ }^{2}$ Land Resource Management, Agriculture and Agri-Food Canada, Brandon Research Centre, Brandon, MB, Canada. ${ }^{3}$ Farm Technology Group, Wageningen University, P.O. Box 17, 6700 AA Wageningen, The Netherlands. ${ }^{4}$ Environmental Sciences Group, Wageningen University, P.O. Box 47, 6700 AA Wageningen, The Netherlands.*Corresponding author:xbwang@caas.ac.cn;dxcai@caas.ac.cn

\begin{abstract}
A major challenge facing China is to meet the increasing food demand of its growing population in the face of decreasing arable land area, while sustaining or improving soil productivity and avoiding adverse environmental impacts from intensive agriculture. This study uses data from China Statistical Yearbooks to analyze trends in regional soil productivity and grain yields in the major grain-producing regions in North China (NC), Northeast China (NE), East China (EC), Central China (CC), and Southwest China (SW), associated with regional fertilizer use and annual climate variation in rainfall and mean temperature over the 20 years. During 1992-2012, the average fertilizer increase rates (in $\mathrm{kg} \mathrm{ha}^{-1}$ year $^{-1}$ ) were in the order of regions $\mathrm{CC}(6.6)>\mathrm{NC}(4.8)>\mathrm{EC}(2.4)>$ $\mathrm{SW}(2.1)>\mathrm{NE}$ (1.3), while yield responses to fertilizer use (with regression model coefficients, in $\mathrm{kg} \mathrm{kg}^{-1}$ ) were in the order: SW $(-0.9)<\mathrm{CC}(1.1)<\mathrm{NC}(1.7)<\mathrm{EC}(5.7)<\mathrm{NE}(9.3)$, showing higher yield responses to fertilizer use for $\mathrm{NE}$ and $\mathrm{EC}$ than for other regions. The changes in regional grain yields also showed higher yield responses to soil-based productivity for $\mathrm{NC}, \mathrm{CC}$, and $\mathrm{SW}$, or to annual climate variability for $\mathrm{CC}$ than for other regions, indicating that other factors (such as inherent soil productivity or annual climate variability could be more important than fertilizer in affecting yields. The strategies for regulating nutrient management are needed considerably based on regional indigenous soil nutrient supply under varying regional climate conditions.
\end{abstract}

Keywords: Cropland, grain yield, soil productivity, fertilizer, fertilizer-use efficiency 


\section{Introduction}

A major challenge facing China is to meet the increasing food demand of its growing population in the face of decreasing arable land area, while sustaining or improving soil productivity and avoiding adverse environmental impacts from intensive agriculture. Soil productivity is the ability of a soil to support crop production, generally measured in terms of yield (Brady, 1974), and is determined by the interaction of soil physical, chemical and biological attributes (Roy et al., 2006). Also, soil productivity was defined as "the capacity to grow a particular plant or plant sequence under a specified management system" (Pierce et al., 1983), and could be assessed by single factor, multi-factor or simulation models by using soil physical and chemical properties (Duan et al., 2009). In China, productivity of two-thirds of the arable land is restricted to below the mid-range (Zhou, 2013), because of a range of soil problems, climate factors, management constraints linked to economic development, and increased land-use intensity (Shi et al., 2010; Zhou, 2013). With the development of industrialized agriculture, China's agricultural intensification has also greatly increased the volume of production, but has forced farmers to increase land use intensity. Intensification has placed increasing pressure on the land, leading to over-use of marginal lands for food production, excess tillage, over-cultivation on the limited croplands that have high potential for multiple cropping, but also increased use of fertilizer inputs often resulting in negative environmental impacts (Liu and Diamond, 2005). The soil nutrient surplus in China has been increasing since the 1980's, particularly in the more developed southeastern provinces (Shen et al., 2005), with the major cereal-producing provinces such as Shandong, Henan and Sichuan maintaining high fertilizer inputs over time (Liu et al., 2009). In these regions, fertilizer applications are often far greater than crop demands, leading to excess soil nutrient accumulation, especially higher nitrogen (Darilek et al., 2009). Positive nutrient balances can build up soil fertility and enhance soil productivity, but can also decrease agronomic fertilizer-use efficiency, and increase the risk of fertilizer loss and potential environment impacts (Peng, 2011). Some suggest that intensive use of arable land will be required in the future to ensure food security in China (Zhou, 2013), but it must be coupled to sustained soil productivity and environmental quality. Maintaining soil productivity and food security under the long-term fertilizer-based intensive cropping system and varying regional climate conditions is a critical concern both for China and globally.

We hypothesize that intensive land use with increased fertilizer use for high grain production on the limited cropland in China, especially during the last 20 years, has influenced the long-term soil productivity, which will in turn have an impact on sustainable food production.

This paper, based on China Statistical Yearbooks 1993-2013, analyzes the trends in regional major grain yields, including the three major grain crops of rice (Oryza sativa), wheat (Triticum aestivum) and maize (Zea mays), associated with fertilizer use in the three major grain croplands and annual climate variation in rainfall and mean temperature over the last 20 years, and assesses the changes in the soil-based productivity of Chinese grain croplands in the major grain-producing regions in North China, Northeast China, East China, and Central \& Southwest China. The assessment provides information on (i) trends in regional grain yield responses to fertilizer use over time, and (ii) changes in regional soil-based productivity under intensive grain production conditions. The aim of the study is to gather useful information 
to guide regional soil nutrient management practices that can sustain soil productivity and enhance crop production capacity under varying regional climate conditions to meet the grand challenge of food production security, health and sustainable development.

\section{Materials and Methods}

\subsection{Site description}

The research sites were located in the 13 major grainproducing provinces, distributed in the following five regions: (1) North China (NC): Hebei, and Inner Mongolia; (2) Northeast China (NE): Heilongjiang, Jilin, and Liaoning; (3) East China (EC): Anhui, Jiangsu, Jiangxi, and Shandong; (4) Central China (CC): Henan, Hubei, and Hunan, and (5) Southwest China (SW): Sichuan (Figure 1). A brief description of the research sites is given in Table 1, which includes soil type, climatic characteristics, major grain crops (including rice, wheat and maize), for each of these provinces, using statistical data averaged from 1992 to 2012, based on China Statistical Yearbooks (NBSC, 1993-2013).

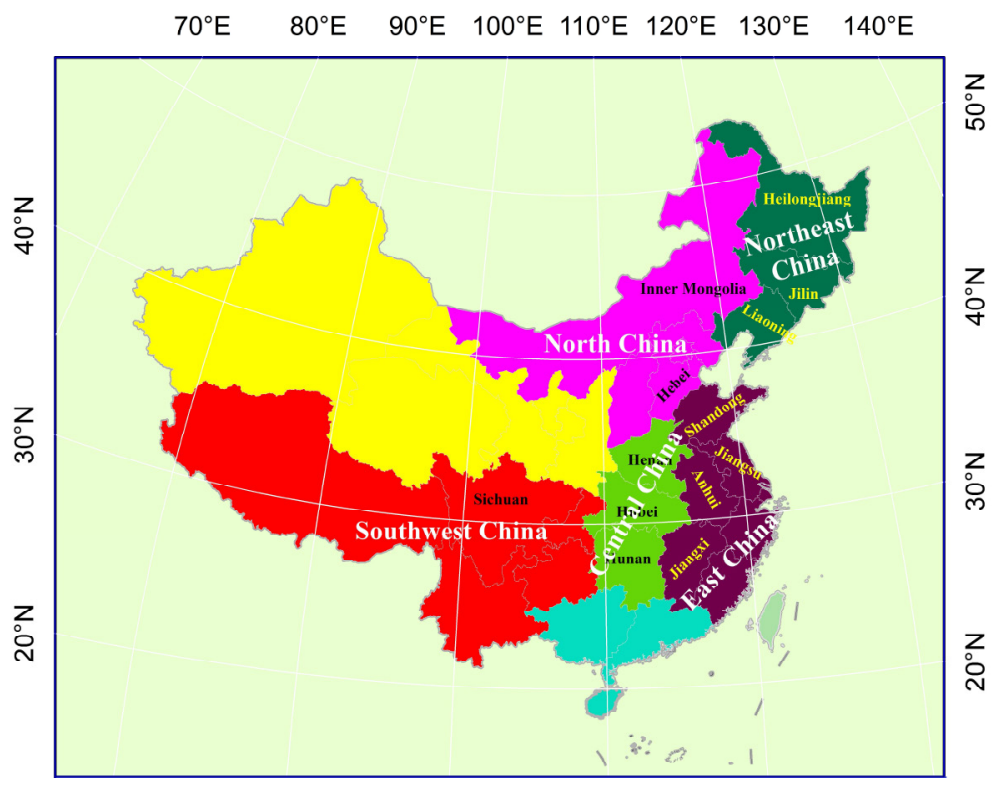

Figure 1. Map of the research sites in the 13 major grain-producing provinces in China in five regions: (1) Northeast China (NE): Heilongjiang, Jilin, and Liaoning; (2) North China (NC): Hebei, and Inner Mongolia; (3) East China (EC): Anhui, Jiangsu, Jiangxi, and Shandong; (4) Central China (CC): Henan, Hubei, and Hunan; and (5) Southwest China (SW): Sichuan provinces. 
Table 1. Characteristics of the 13 major grain-producing provinces, data over the period 1992-2012 (Source: National Bureau of Statistics of China, 1993-2013).

\begin{tabular}{|c|c|c|c|c|c|c|c|c|}
\hline \multirow[t]{2}{*}{ Site } & \multirow[t]{2}{*}{ Soil type $\mathrm{e}^{\dagger}$} & \multicolumn{3}{|c|}{$\begin{array}{c}\text { Annual rainfall } \\
(\mathbf{m m})\end{array}$} & \multicolumn{3}{|c|}{$\begin{array}{c}\text { Annual avg. } \\
\text { temperature }\left({ }^{\circ} \mathrm{C}\right)\end{array}$} & \multirow[t]{2}{*}{ Major crops } \\
\hline & & Min. & $\operatorname{Max}$ & Ave. & Min. & $\operatorname{Max}$ & Ave. & \\
\hline \multicolumn{9}{|l|}{ North China (NC) } \\
\hline Hebei, & Cinnamon soils /Fluvo-aquic soils & 303.2 & 1097.1 & 527.8 & 13.5 & 15.0 & 14.2 & Corn/Wheat \\
\hline Inner Mongolia & Castanozems /Aeolian soils & 177.1 & 653.1 & 394.7 & 6.5 & 9.0 & 7.7 & Corn/Wheat \\
\hline \multicolumn{9}{|l|}{ Northeast China (NE) } \\
\hline Liaoning & Brown earths & 479.7 & 1036.6 & 679.5 & 7.2 & 9.7 & 8.5 & Corn/Rice \\
\hline Jilin, & Black soils /Dark-brown earths /Chernozems & 389.9 & 878.3 & 562.5 & 5.2 & 7.7 & 6.3 & Corn/Rice \\
\hline Heilongjiang, & Black soils /Dark-brown earths & 385.2 & 826.4 & 528.2 & 4.4 & 6.7 & 5.2 & Corn/Rice \\
\hline \multicolumn{9}{|l|}{ East China (EC) } \\
\hline Jiangsu, & Paddy soils /Red earths & 647.9 & 1623.5 & 1078.5 & 15.1 & 17.3 & 16.3 & Rice/Wheat \\
\hline Anhui, & Paddy soils /Fluvo-aquic soils & 697.2 & 1413.4 & 988.7 & 15.5 & 17.3 & 16.5 & Rice/Wheat \\
\hline Jiangxi, & Red earths /Paddy soils & 1108.6 & 2366.5 & 1662.7 & 17.4 & 19.2 & 18.3 & Rice \\
\hline Shandong & Fluvo-aquic soils /Brown earths & 455.7 & 1090.0 & 737.9 & 13.8 & 16.0 & 14.8 & Corn/Wheat \\
\hline \multicolumn{9}{|l|}{ Central China $(\mathrm{CC})^{\circ}$} \\
\hline Henan (Central) & Fluvo-aquic soils /Cinnamon soils & 354.9 & 1010.6 & 652.6 & 14.0 & 15.9 & 15.1 & Corn/Wheat \\
\hline Hubei (Central) & Yellow-brown earths /Paddy soils / Red earths & 899.8 & 1739.2 & 1250.8 & 16.2 & 18.5 & 17.4 & Rice/Wheat \\
\hline Hunan (Central) & Red earths /Paddy soils & 932.8 & 1824.3 & 1456.1 & 16.5 & 18.8 & 17.7 & Rice \\
\hline \multicolumn{9}{|l|}{ Southwest China (SW) } \\
\hline Sichuan (Southwest) & Paddy soils /Purplish soils & 610.9 & 1060.4 & 810.3 & 15.8 & 17.4 & 16.6 & Rice/Wheat/Corn \\
\hline
\end{tabular}

$\dagger$ Soil classification based on ISS-CAS (2003).

In China's 31 provinces, autonomous regions, and municipalities directly under the central government, there are 13 major grain producing regions. According to national statistical data in 2012 (NBSC, 2013), the total major grain (including rice, wheat and maize) production accounted for about $90 \%$ of the national total grain production. The major grain production in the top 13 major grain-producing provinces accounted for $77 \%$ of the national total major grain production, accounting for about $10 \%, 19 \%$, $24 \%, 20 \%$, and $5 \%$ of the national total, respectively, for $\mathrm{NC}, \mathrm{NE}, \mathrm{EC}, \mathrm{CC}$, and $\mathrm{SW}$.

\subsection{Data collection and analysis}

The statistical data including fertilizer inputs, major grain yields, and annual climate data in the five re- gions (NC, NE, EC, CC, and SW) involved in the 13 grain-producing provinces for the period 1992-2012 were gathered from the China Statistical Yearbooks (NBSC, 1993-2013). Data for fertilizer inputs include the total $\mathrm{NPK}\left(\mathrm{N}+\mathrm{P}_{2} \mathrm{O}_{5}+\mathrm{K}_{2} \mathrm{O}\right)$ nutrient inputs from nitrogenous, phosphate, potash and compound fertilizers. Data for major grain yields include the total grain yields of three grain crops, including rice, wheat, and maize. Data for annual climate variability include the data of annual rainfall (AR) and annual mean temperature (AMT). The data were used to analyze the trends in regional grain yields (GY) associated with fertilizer use (F) and annual climate variation in AR and AMT over the last 20 years, and to assess the changes in the regional grain yield responses to fertilizer use. They were also used to estimate the partial factor productivity of applied fertilizer (PFP). 


\subsection{Calculations and estimations}

The trends in regional grain yields (GY) were analyzed by the statistical models. Statistical analysis was conducted using the REG procedure of the SAS institute, Inc. (2004). Multiple linear regression models were fitted to describe the relationships between regional grain yield (GY) and added fertilizer (F), annual rainfall (AR), annual mean temperature (AMT), and year-time variable (YR). Then the statistical models, in which the GY (or GYf, the fertilizer-based yield) was calculated as function of F, AR, AMT, and YR, were also used to estimate the soil-based productivity (GYo, as function of AR, AMT, and YR, when $F=0$ ) as follows:

$$
\begin{gathered}
G Y=b_{0}+b_{1} \times F+b_{2} \times A R+b_{3} \times A M T+b_{4} \times Y R \quad \text { Equation } 1 \\
\text { where } \mathrm{GY}=\text { grain yield, in } \mathrm{kg} \mathrm{ha}^{-1} ; \\
\mathrm{F}=\text { fertilizer rate (NPK nutrient input rate), } \mathrm{kg} \mathrm{ha}^{-1} ; \\
\mathrm{AR}=\text { annual rainfall, } \mathrm{mm} ; \\
\mathrm{AMT}=\text { annual mean temperature, }{ }^{\mathrm{o}} \mathrm{C} ; \\
\mathrm{YR}=\text { time, in year; } \\
\text { and } \mathrm{b}_{0}, \mathrm{~b}_{1}, \mathrm{~b}_{2}, \mathrm{~b}_{3}, \text { and } \mathrm{b}_{4}=\text { coefficients. }
\end{gathered}
$$

The fertilizer partial factor productivity (PFP) is broadly used to measure fertilizer-use efficiency as it provides an aggregate efficiency index that includes contributions to crop yield derived from uptake of indigenous soil nutrient supply, fertilizer uptake effi- ciency, and the efficiency with which fertilizer acquired by the plant is converted to grain yield (Dobermann, 2005). The PFP index (the ratio of the grain yield to the applied fertilizer rate, in $\mathrm{kg}$ grain $\mathrm{kg}^{-1}$ ) was calculated as or can be expressed as:

$$
\begin{array}{ll}
P F P=G Y f / F & \text { Equation } 2 \\
\text { or } & \\
P F P=(G Y o+\Delta G Y) / F & \text { Equation 3 }
\end{array}
$$

where GYf \& GYo are grain yields with \& without fertilizer (F), and $\Delta G Y$ is the incremental yield increase that results from fertilizer use $(\Delta \mathrm{GY}=\mathrm{GYf}$ $\mathrm{GYo}) . \Delta \mathrm{GY} / \mathrm{F}$ defined as the agronomic fertilizer-use efficiency (AE) is the incremental efficiency from applied fertilizer (in $\mathrm{kg}$ yield increase per $\mathrm{kg}$ fertilizer use) or proportional to the benefit-cost ratio from investment in fertilizer inputs (Novoa and Loomis, 1981). GYo/F is a mathematical term derived from separating the yield supported by indigenous nutrient from that obtained in response to fertilizer use (Cassman et al., 1996). 


\section{Results}

\subsection{Trends in regional major grain production over the last 20 years}

Based on China Statistical Yearbooks (NBSC, 19932013), the trends in regional sown area: the total sown area, and the major cropland area (including rice, wheat and maize cropland), and the regional grain production: the total grain production, and the major grain production are shown in Figure 2. The major cropland area $\%$ of the total sown area changed from $51 \%$ to $57 \%, 58 \%$ to $70 \%, 59 \%$ to $62 \%, 59 \%$ to $56 \%$, and $56 \%$ to $48 \%$, respectively, for regions $\mathrm{NC}, \mathrm{NE}$, EC, CC, and SW during 1992-2012, while the major grain production of the total grain production changed from $82 \%$ to $88 \%, 84 \%$ to $91 \%, 89 \%$ to $95 \%, 92 \%$ to $95 \%$, and $81 \%$ to $81 \%$, respectively. The results showed that the changes in the major grain production were significantly influenced by the changes in major cropland area for the five regions (Figure 2).
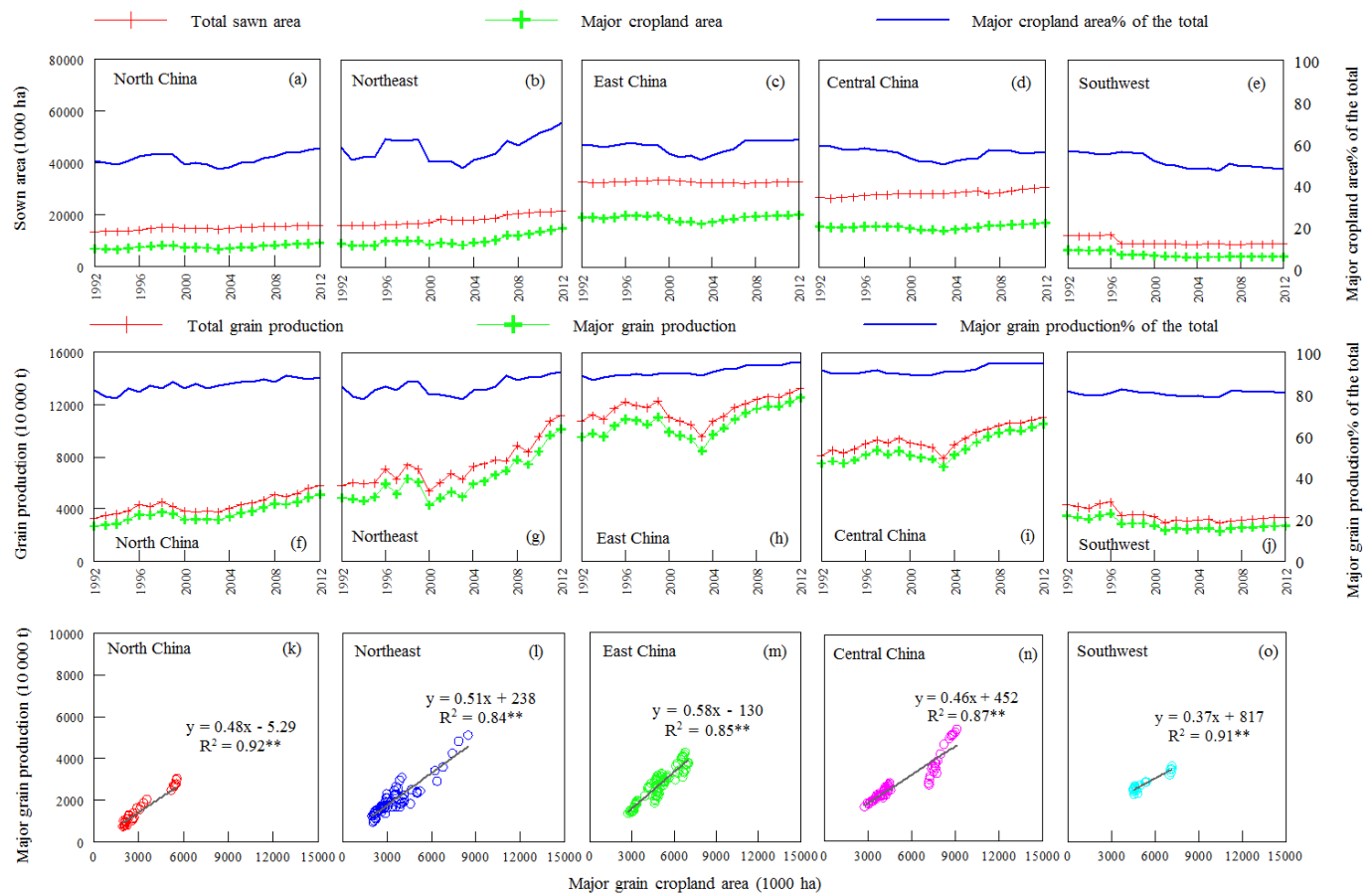

Figure 2. Trends in the regional sown area (a-e): the total sown area, the major cropland area (including rice, wheat and maize cropland), and the major cropland area $\%$ of the total sown area; the regional grain production $(\mathrm{f}-\mathrm{j})$ : the total grain production, the major grain production, and the major grain production $\%$ of the total grain production, as well as the relationships between the changes in the major grain production and the changes in the major cropland area (k-o) in North China, Northeast China, East China, Central China, and Southwest China during 1992-2012 (Source: National Bureau of Statistics of China, 1993-2013). 
Based on the statistical data (NBSC, 1993-2013), the major grain production for regions $\mathrm{NC}, \mathrm{NE}, \mathrm{EC}, \mathrm{CC}$, and SW changed by about $40 \%, 30 \%, 10 \%, 10 \%$, and $-18 \%$ from 1992 to 1998 , but decreased by $15 \%$, $22 \%, 19 \%, 13 \%$, and $16 \%$ from 1998 to 2003 , and then increased by $62 \%, 107 \%, 48 \%, 47 \%$, and $11 \%$ from 2003 to 2012, respectively. Data on yield trend analysis showed China's grain yield per unit area reached record highs in 1998, but has stagnated since then; this was mainly attributed to the rapidly growth in agricultural fertilizer consumption since the end of the 1980s (Xin et al., 2012).

\subsection{Changes in regional grain yields over the last} 20 years

Based on the Statistical Yearbooks (NBSC, 19932013, the changes in fertilizer use and annual climate variability in AR and AMT in the major grain-producing regions over the last 20 years are shown in Figure 3. During 1992-2012, annual variations in AR were large, ranging from 177 to 1097,385 to 1037,456 to 2367,355 to 1824 , and 611 to 1060 $\mathrm{mm}$, respectively, for $\mathrm{NC}, \mathrm{NE}, \mathrm{EC}, \mathrm{CC}$, and $\mathrm{SW}$, correspondingly with coefficients of variation (CV) of $38 \%, 24 \%, 38 \%, 36 \%$, and $16 \% \%$, while annual variations in AMT ranged from 6.5 to 15.0 , 4.4 to $9.7,13.8$ to $19.2,14.0$ to 18.8 , and 15.8 to $17.4{ }^{\circ} \mathrm{C}$, respectively, correspondingly with $\mathrm{CVs}$ of $31 \%, 28 \%, 8 \%, 8 \%$, and $3 \%$. The fertilizer use on weighted average changed from 198 to 324,217 to 268, 302 to 379,263 to 412 , and 205 to $255 \mathrm{~kg} \mathrm{ha}^{-1}$, respectively, for $\mathrm{NC}, \mathrm{NE}, \mathrm{EC}, \mathrm{CC}$, and $\mathrm{SW}$ during 1992-2012, corresponding to average increase rates of 4.8, 1.3, 2.4, 6.6, and $2.1 \mathrm{~kg} \mathrm{ha}^{-1}$ year-1 (Figure 3).

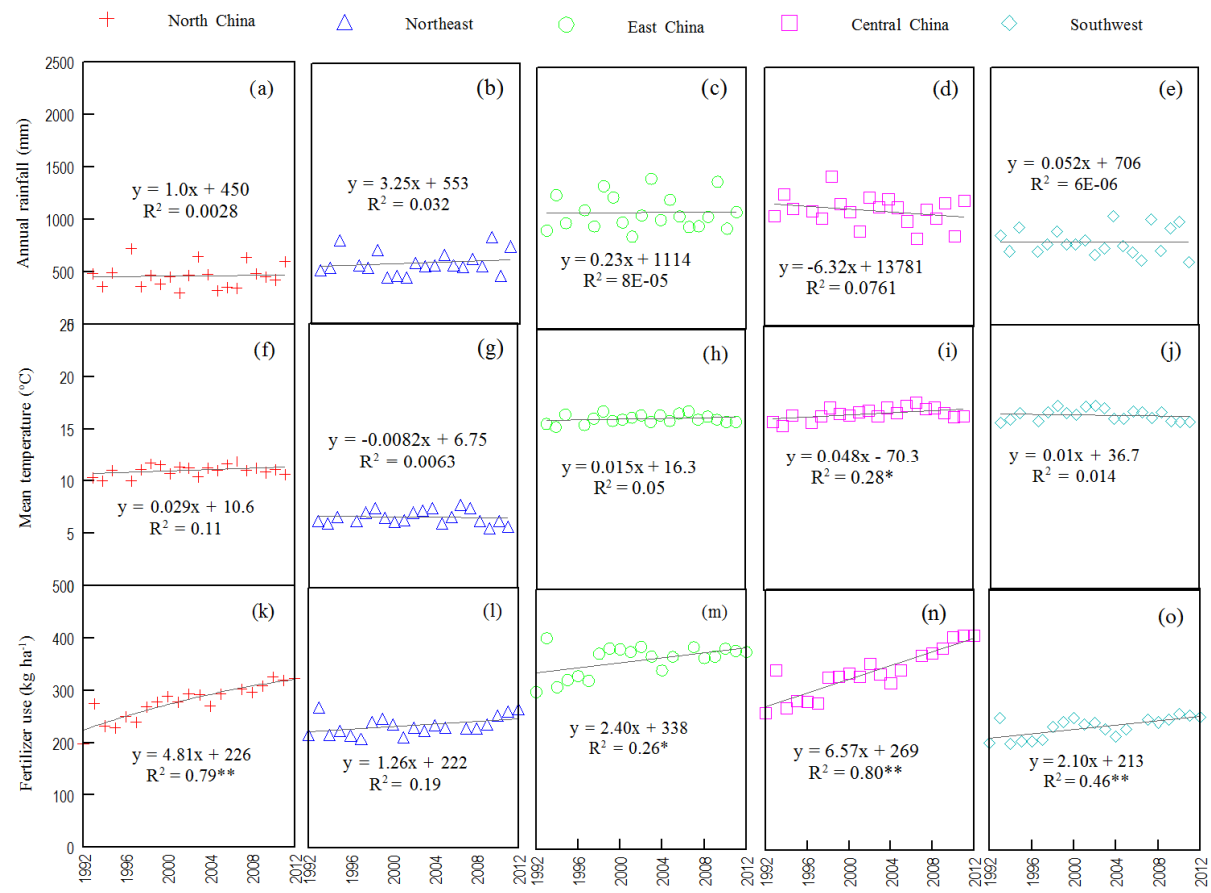

Figure 3. Trends in annual rainfall $(\mathrm{AR}, \mathrm{mm})(\mathrm{a}-\mathrm{e})$, annual mean temperature $\left(\mathrm{AMT},{ }^{\circ} \mathrm{C}\right)(\mathrm{f}-\mathrm{j})$, and fertilizer use $(\mathrm{F}$, $\left.\mathrm{kg} \mathrm{ha}^{-1}\right)(\mathrm{k}-\mathrm{o})$ in North China, Northeast China, East China, Central China, and Southwest China during 1992-2012 (Source: National Bureau of Statistics of China, 1993-2013). 
The statistical models for analysis of regional yieldinfluencing factors (in Table 2) could satisfactorily explain the increasing trends in regional grain yields (GY) over the last 20 years, in responses to fertilizer inputs (F), annual climate variability in AR and AMT, and year-time variable (YR), accounting for about $80 \%, 59 \%, 61 \%, 83 \%$, and $70 \%$ of yield variability, respectively, for regions $\mathrm{NC}, \mathrm{NE}, \mathrm{EC}, \mathrm{CC}$, and $\mathrm{SW}$. The regional grain yields increased over the last 20 years, which were significantly related to time variable by year changes and generally responded positively to fertilizer use as assessed using multiple regression analysis (Table 2). The average yield responses to increased fertilizer rates (with regression model coefficients, in $\mathrm{kg} \mathrm{kg}^{-1}$ ) were in the order:
$\mathrm{NE}(9.3)>\mathrm{EC}(5.7)>\mathrm{NC}(1.7)>\mathrm{CC}(1.1)>\mathrm{SW}$ $(-0.9)$ during the period 1992-2012, while the average rates of fertilizer increase were in the order (in $\mathrm{kg} \mathrm{ha}^{-1}$ year $\left.^{-1}\right)$ : NE $(1.3)<\mathrm{SW}(2.1)<\mathrm{EC}(2.4)<\mathrm{NC}$ (4.8) < CC (6.6) (Figure 3), showing significantly higher yield responses to fertilizer use for NE and $\mathrm{EC}$ than for other regions. The changes in regional yields were not affected by $\mathrm{AR}$, except for $\mathrm{CC}$, but significantly positively related to AMT for CC and $\mathrm{EC}$ but not for $\mathrm{NC}, \mathrm{NE}$, and $\mathrm{SW}$, correspondingly with regression model coefficients (in $\mathrm{kg}{ }^{\circ} \mathrm{C}$ ) of 272 , $128,-68,-136$, and -48 (Table 2), indicating that yields in some regions might be more sensitive to AMT and AR than fertilizer (such as in CC).

Table 2. Coefficients of the regression models for regional major grain yields (GY), as function of fertilizer (F), annual rainfall (AR), annual mean temperature (AMT), and year-time variable (YR), in North China (NC), Northeast China (NE), East China (EC), Central China (CC), and Southwest China (SW) for the period 1992-2012 (Source: National Bureau of Statistics of China, 1993-2013).

\begin{tabular}{llccccc}
\hline Regions & Param. & Intercept & F & AR & AMT & YR $^{\dagger}$ \\
\hline $\mathrm{NC}\left(\mathrm{R}^{2}=0.80^{* *}, \mathrm{~N}=37\right)$ & $\mathrm{PE}$ & 4218 & 1.69 & 0.21 & -67.8 & 71.1 \\
& $\mathrm{SE}$ & 210 & 1.74 & 0.27 & 43.2 & 11.4 \\
& tValue & 20.1 & 0.97 & 0.81 & -1.57 & 6.25 \\
& $\mathrm{Pr}>|\mathrm{t}|$ & $<.0001$ & 0.34 & 0.43 & 0.13 & $<.0001$ \\
$\mathrm{NE}\left(\mathrm{R}^{2}=0.59^{* *}, \mathrm{~N}=56\right)$ & $\mathrm{PE}$ & 3912 & 9.29 & 0.21 & -136.2 & 34.1 \\
& $\mathrm{SE}$ & 461 & 1.42 & 0.65 & 76.8 & 14.2 \\
& tValue & 8.48 & 6.53 & 0.32 & -1.77 & 2.39 \\
& $\mathrm{Pr}>|\mathrm{t}|$ & $<.0001$ & $<.0001$ & 0.75 & 0.082 & 0.020 \\
$\mathrm{EC}\left(\mathrm{R}^{2}=0.61^{* *}, \mathrm{~N}=75\right)$ & $\mathrm{PE}$ & 772 & 5.69 & 0.21 & 128.2 & 38.0 \\
& $\mathrm{SE}$ & 1083 & 0.80 & 0.15 & 57.8 & 7.86 \\
& $\mathrm{tValue}$ & 0.71 & 7.08 & 1.44 & 2.22 & 4.83 \\
& $\mathrm{Pr}>|\mathrm{t}|$ & 0.48 & $<.0001$ & 0.15 & 0.03 & $<.0001$ \\
$\mathrm{CC}\left(\mathrm{R}^{2}=0.83^{* *}, \mathrm{~N}=56\right)$ & $\mathrm{PE}$ & -83.3 & 1.13 & 0.29 & 272.3 & 43.8 \\
& $\mathrm{SE}$ & 652 & 0.65 & 0.13 & 41.2 & 7.42 \\
& $\mathrm{tValue}$ & -0.13 & 1.73 & 2.21 & 6.6 & 5.91 \\
& $\mathrm{Pr}>|\mathrm{t}|$ & 0.90 & 0.089 & 0.031 & $<.0001$ & $<.0001$ \\
$\mathrm{SW}\left(\mathrm{R}^{2}=0.70^{* *}, \mathrm{~N}=18\right)$ & $\mathrm{PE}$ & 5794 & -0.89 & 0.041 & -47.5 & 47.0 \\
& $\mathrm{SE}$ & 1853 & 3.69 & 0.40 & 97.8 & 11.0 \\
& $\mathrm{tValue}$ & 3.13 & -0.24 & 0.1 & -0.49 & 4.27 \\
& $\mathrm{Pr}>|\mathrm{t}|$ & 0.0074 & 0.81 & 0.92 & 0.63 & 0.0008 \\
\hline
\end{tabular}

$\dagger \mathrm{PE}=$ Parameter Estimate; $\mathrm{SE}=$ Standard Error; $\mathrm{Pr}=$ probability-value $(P$-value $)$. 
The annual variations in the soil-based productivity (GYo) were also calculated as a function of $F$ (where $\mathrm{F}=0$ ), AR, AMT, and YR using the statistical models based on the equations in Table 2, then compared to the fertilizer-based yields (GYf) from the Statistical Yearbooks in the five regions (Figure 4). The changes in GYo on weighted average from 1992 to 2012 ranged from 3542 to 5004,3216 to 4026,2964 to 3781,4441 to 5506 , and 5079 to $6006 \mathrm{~kg} \mathrm{ha}^{-1}$ for
NC, NE, EC, CC, and SW. Both GYf and GYo for the five regions increased from 1992 to 2012, while the average increase rates (in $\mathrm{kg}$ year $^{-1}$ ) in NC, NE, EC, CC, and SW were 70, 53, 52, 68, and 44 for GYf, as compared to $71,35,40,53$, and 48 for GYo, respectively (Figure 4). The GYf and GYo for the period 1992-2012 were significantly positively correlated for $\mathrm{NC}, \mathrm{CC}$, and $\mathrm{SW}\left(\mathrm{R}^{2}=0.72 * *, 0.80^{* *}\right.$, and $0.44^{* *}$, respectively), but not for EC and NE (Figure 5).

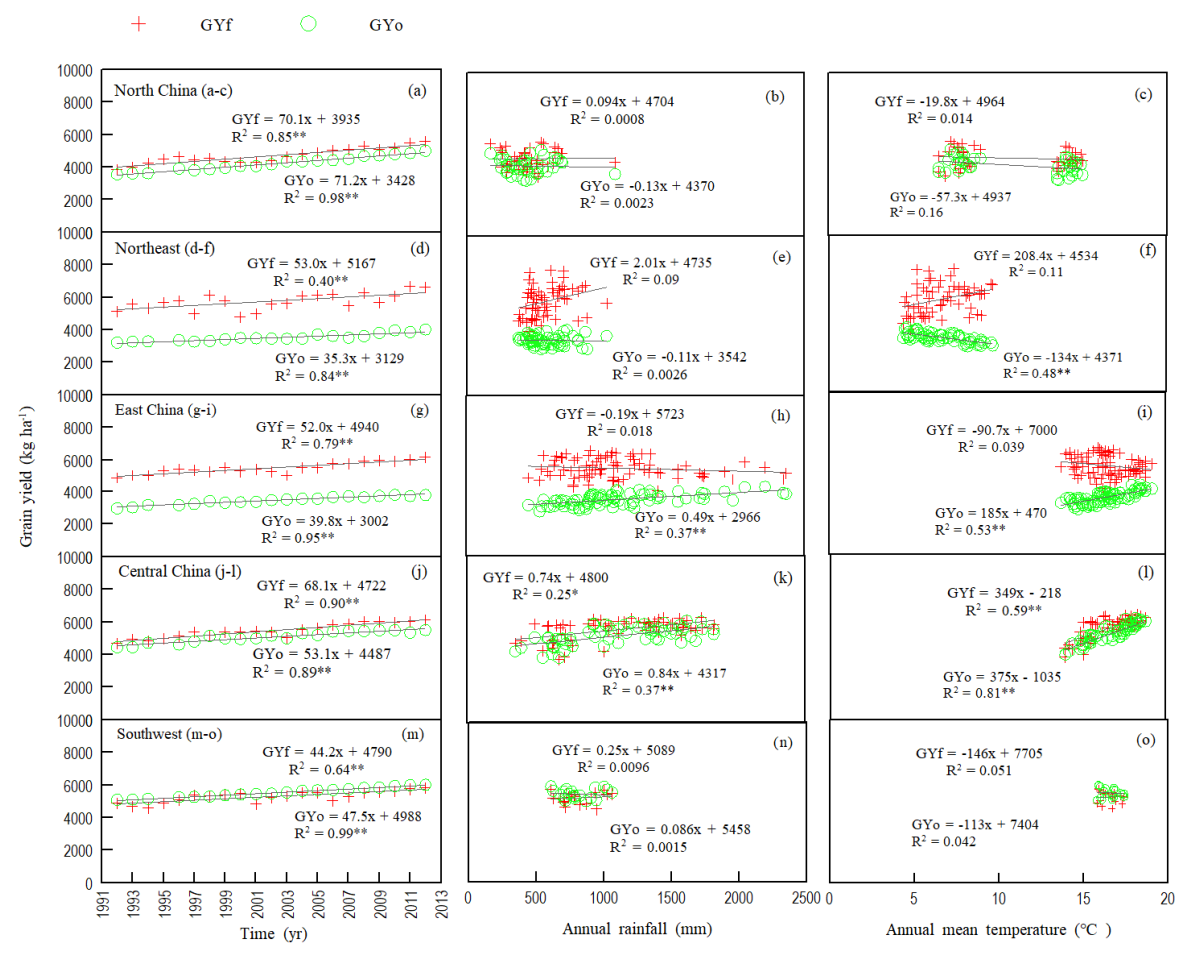

Figure 4. Changes in fertilizer-based grain yields (GYf, grain yield with fertilizer added based on China statistical yearbook 1993-2013), and soil-based productivity (GYo, grain yield without fertilizer added estimated based on the equations in Table 2), in responses to time (year, YR), annual rainfall (AR) and annual mean temperature (AMT) in North China (NC, a-c), Northeast China (NE, d-f), East China (EC, g-i), Central China (CC, j-1), and Southwest China (SW, m-o) for the period 1992-2012. 


\subsection{Changes in fertilizer partial factor productivity}

The annual variations in PFP (fertilizer partial factor productivity) for the five regions were showed in Figure 5. During 1992-2012, PFP on weighted average changed from 19.5 to $17.3,23.6$ to $24.8,16.2$ to $16.2,17.8$ to 14.9 , and 23.8 to $22.7 \mathrm{~kg} \mathrm{~kg}^{-1}$, respecti- vely, for NC, NE, EC, CC, and SW, as fertilizer use increased over time. There were significantly negative relationships between regional PFP and fertilizer use from 1992 to 2012 (Figure 5). There were significantly positive relationships between PFP and GYo for NE, EC, and CC, but not for NC, and SW (Figure 5).

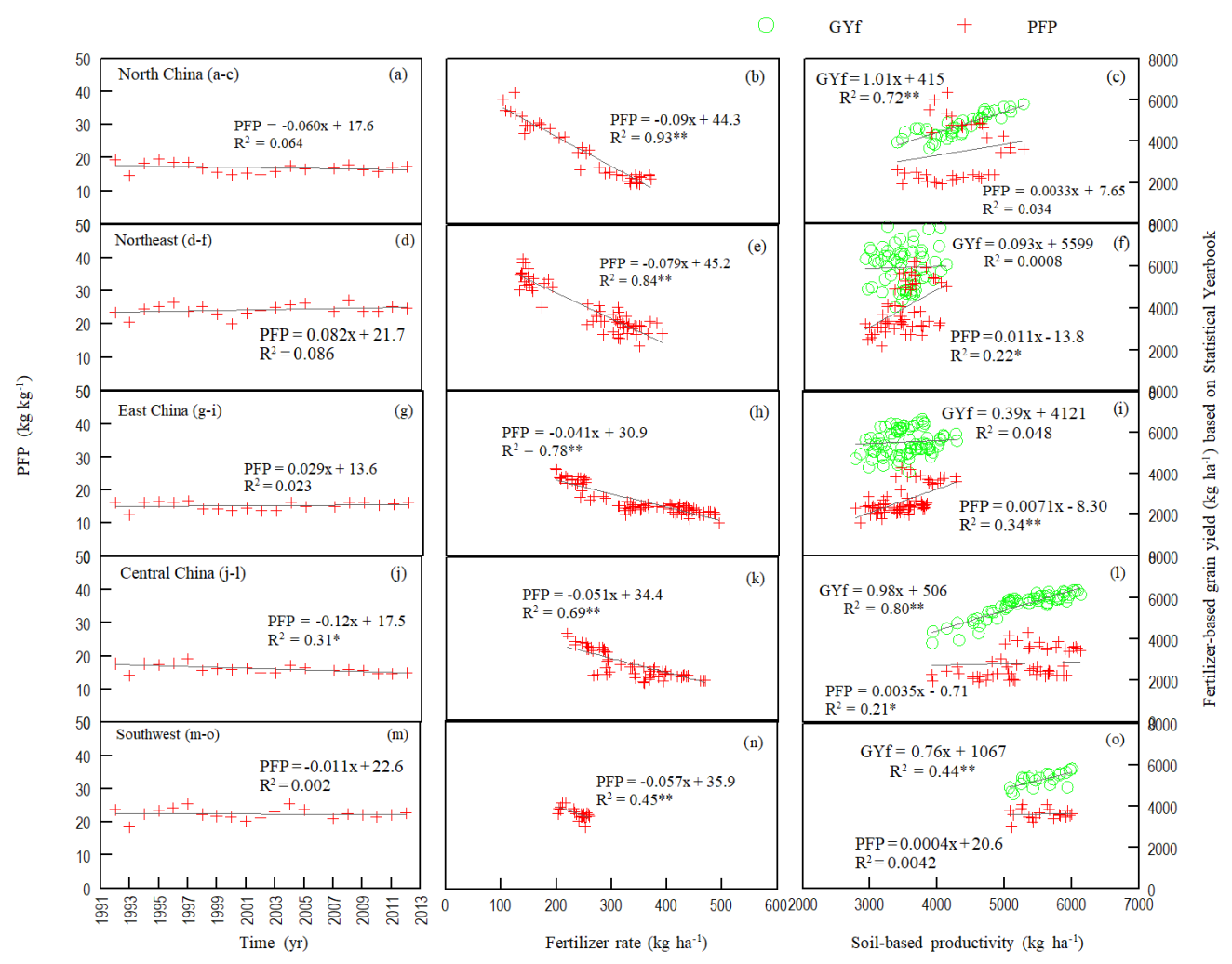

Figure 5. Changes in fertilizer partial factor productivity (PFP), in responses to time (year, YR), fertilizer rate (F) and soil-based productivity (GYo), and relationships between fertilizer-based grain yields (GYf, grain yields with fertilizer added based on Statistical Yearbook 1992-2013) and soil-based productivity (GYo, grain yields without fertilizer added estimated based on the equations in Table 2) in North China (NC, a-c), Northeast China (NE, d-f), East China (EC, g-i), Central China (CC, j-1), and Southwest China (SW, m-o) for the period 1992-2012. 
Table 3 showed that the changes in PFP, and its two components (AE and GYo/F) between 1992 and 2012. Such as in 2012, weighted average PFP (in $\mathrm{kg} \mathrm{kg}^{-1}$ ) followed the order $\mathrm{NE}(24.8)>\mathrm{SW}(22.7)>\mathrm{NC}$ (17.3) $>\mathrm{EC}(16.2)>\mathrm{CC}(14.9)$, where the $\mathrm{AE}$ component (in $\left.\mathrm{kg} \mathrm{kg}^{-1}\right)$ of NE (9.7), SW (-0.8), NC (1.8), EC (6.3) and $\mathrm{CC}$ (1.5), respectively, as compared to the $\mathrm{GYo} / \mathrm{F}$ component (in kg kg-1) of NE (15.0), SW (23.5), NC (15.5), EC (10.0), and CC (13.4) accounted for about $61 \%, 103 \%, 89 \%, 61 \%$, and $90 \%$ of PFP.

Table 3. Regional mean fertilizer rate (F), major grain yields with and without fertilizer (GYf and GYo), fertilizer partial factor productivity $(\mathrm{PFP}=\mathrm{GYo} / \mathrm{F}+\mathrm{AE})$, and $\mathrm{PFP}$ components $(\mathrm{GYo} / \mathrm{F}$ and $\mathrm{AE}$, where $\mathrm{AE}=\Delta \mathrm{GY} / \mathrm{F})$, in North China (NC), Northeast China (NE), East China (EC), Central China (CC), and Southwest China (SW), using statistical data weighted averaged over 1992-2012 (Source: National Bureau of Statistics of China, 1993-2013).

\begin{tabular}{|c|c|c|c|c|c|c|}
\hline Regions & Indices & 1992 & 2012 & $\begin{array}{c}\text { Diff. } \\
(2012-1992)\end{array}$ & $\begin{array}{c}\text { Changing trend } \\
\text { during 1992-2012 }\end{array}$ & $R^{2}$ value \\
\hline \multirow[t]{6}{*}{$\mathrm{NC}$} & $\mathrm{F}$ & 198 & 324 & 125 & $y=4.81 x+226$ & $\mathrm{R}^{2}=0.79 * *$ \\
\hline & GYf & 3858 & 5600 & 1741 & $y=70.1 x+3935$ & $\mathrm{R}^{2}=0.85^{* *}$ \\
\hline & GYo & 3542 & 5004 & 1462 & $y=71.2 x+3428$ & $\mathrm{R}^{2}=0.98^{* *}$ \\
\hline & PFP & 19.5 & 17.3 & -2.2 & $y=-0.060 x+17.6$ & $\mathrm{R}^{2}=0.064$ \\
\hline & $\mathrm{GYo} / \mathrm{F}$ & 17.9 & 15.5 & -2.4 & & \\
\hline & $\mathrm{AE}$ & 1.6 & 1.8 & 0.2 & & \\
\hline \multirow[t]{6}{*}{$\mathrm{NE}$} & $\mathrm{F}$ & 217 & 268 & 51 & $y=1.26 x+222$ & $\mathrm{R}^{2}=0.19$ \\
\hline & GYf & 5123 & 6636 & 1514 & $y=53.0 x+5167$ & $\mathrm{R}^{2}=0.40^{* *}$ \\
\hline & GYo & 3216 & 4026 & 810 & $y=35.3 x+3129$ & $\mathrm{R}^{2}=0.84 * *$ \\
\hline & PFP & 23.6 & 24.8 & 1.2 & $y=0.082 x+21.7$ & $\mathrm{R}^{2}=0.086$ \\
\hline & $\mathrm{GYo} /$ & 14.8 & 15.0 & 0.2 & & \\
\hline & $\mathrm{AE}$ & 8.8 & 9.7 & 1.0 & & \\
\hline \multirow[t]{6}{*}{$\mathrm{EC}$} & $\mathrm{F}$ & 302 & 379 & 77 & $\mathrm{y}=2.40 \mathrm{x}+338$ & $\mathrm{R}^{2}=0.26^{*}$ \\
\hline & GYf & 4885 & 6160 & 1274 & $\mathrm{y}=52.0 \mathrm{x}+4940$ & $\mathrm{R}^{2}=0.79^{* *}$ \\
\hline & GYo & 2964 & 3781 & 817 & $y=39.8 x+3002$ & $\mathrm{R}^{2}=0.95^{* *}$ \\
\hline & PFP & 16.2 & 16.2 & 0.1 & $y=0.029 x+13.6$ & $\mathrm{R}^{2}=0.023$ \\
\hline & $\mathrm{GYo} / \mathrm{F}$ & 9.8 & 10.0 & 0.2 & & \\
\hline & $\mathrm{AE}$ & 6.4 & 6.3 & -0.1 & & \\
\hline \multirow[t]{6}{*}{$\mathrm{CC}$} & $\mathrm{F}$ & 263 & 412 & 149 & $y=6.57 x+269$ & $\mathrm{R}^{2}=0.80^{* *}$ \\
\hline & GYf & 4689 & 6126 & 1437 & $y=68.1 x+4722$ & $\mathrm{R}^{2}=0.90 * *$ \\
\hline & GYo & 4441 & 5506 & 1065 & $y=53.1 x+4487$ & $\mathrm{R}^{2}=0.89 * *$ \\
\hline & PFP & 17.8 & 14.9 & -3.0 & $y=-0.12 x+17.5$ & $\mathrm{R}^{2}=0.31^{*}$ \\
\hline & $\mathrm{GYo} / \mathrm{F}$ & 16.9 & 13.4 & -3.5 & & \\
\hline & $\mathrm{AE}$ & 0.9 & 1.5 & 0.6 & & \\
\hline \multirow[t]{6}{*}{ SW } & $\mathrm{F}$ & 205 & 255 & 50 & $y=2.10 x+213$ & $\mathrm{R}^{2}=0.46^{* *}$ \\
\hline & GYf & 4891 & 5810 & 919 & $y=44.2 x+4790$ & $\mathrm{R}^{2}=0.64 * *$ \\
\hline & GYo & 5079 & 6006 & 927 & $y=47.5 x+4988$ & $\mathrm{R}^{2}=0.99 * *$ \\
\hline & PFP & 23.8 & 22.7 & -1.1 & $y=-0.011 x+22.6$ & $\mathrm{R}^{2}=0.002$ \\
\hline & $\mathrm{GYo} /$ & 24.7 & 23.5 & -1.2 & & \\
\hline & $\mathrm{AE}$ & -0.9 & -0.8 & 0.1 & & \\
\hline
\end{tabular}

NS, not significant $(\mathrm{P}>0.05)$, and sig, significant $(\mathrm{P}<0.05)$ at the 0.05 probability level. *Significant at $\mathrm{R}<0.05 ; * *$ Significant at $\mathrm{R}<0.01$. Indices units: $\mathrm{F}\left(\mathrm{kg} \mathrm{ha}^{-1}\right)$, GYf $\left(\mathrm{kg} \mathrm{ha}^{-1}\right)$, GYo $\left(\mathrm{kg} \mathrm{ha}^{-1}\right)$, PFP $\left(\mathrm{kg} \mathrm{kg}^{-1}\right), \mathrm{GYo} / \mathrm{F}\left(\mathrm{kg} \mathrm{kg}^{-1}\right), \mathrm{AE}\left(\mathrm{kg} \mathrm{kg}^{-1}\right)$. 


\section{Discussion}

According to an investigation in China, using the national agricultural sub-county data and the second national soil survey data, the proportion of low-yield farmlands had decreased from $50 \%$ to $29 \%$ from 1985 to 2008 , while the medium- and high-yield farmlands had increased from $25 \%$ to $38 \%$ and from $25 \%$ to $34 \%$, respectively (Shi et al., 2010). However, the low- and medium-yield farmlands in China are still large (about 66\%), mainly distributed in Northeast China, North China, and the lower-middle reaches of Yangtze River (Shi et al., 2010). It is important to understand the impacts of a continuous increase in fertilizer use on regional yield differences and yield trends, and the implications that these effects may have for increasing yield potentials by improving the low-medium yield farmlands and sustaining soil productivity in the major food production regions of China.

\subsection{Factors influencing regional grain yields over the} last 20 years

The regional yield differences and yield trends may be attributable to a number of factors such as agroecological zone, crop type, high-input compared with low-input level practices, and management experience (Zundel and Kilcher, 2007). In our study, changes in both GYf (fertilizer-based yields) and GYo (soil-based productivity) for the five regions showed significant increasing trends over time from 1992 to 2012 (Figure 4). The significantly positive relationships between GYf and GYo for the period 1992-2012 for NC, CC, and SW, but not for NE and EC (Figure 5), could explain higher yield responses to fertilizer use for NE and EC than for NC, CC, and SW (Table 2 ), while other factors, such as annual climate variability for CC (Figure 4, and Table 2) and soil-based productivity (or inherent soil productivity) for $\mathrm{NC}$,
$\mathrm{CC}$, and SW, could be more important than fertilizer in affecting yields. The regression analysis of regional yield-limiting factors for the period 1992-2012 also showed that fertilizer appeared to be a more important yield-limiting factor for regions $\mathrm{NE}$ and $\mathrm{EC}$ than for $\mathrm{NC}, \mathrm{CC}$, and $\mathrm{SW}$, while yields in some regions especially for $\mathrm{CC}$ showed more sensitive to annual climate variability (both AMT and AR) than fertilizer (Table 2). The increasing trends in regional yields were significantly related to year-time variable (Table 2 ), indicating that annual variations in yields may also be attributed to some other factors, probably due to increased soil fertility or water availability related to improved farming practices.

With recurring application of mineral fertilizers matched to yield demands, soil fertility in China has improved in terms of soil nutrient status, but also soil organic carbon (SOC) since the 1980s (Sun et al., 2010). However, as several long-term field studies observed, excessive soil fertility, especially $\mathrm{N}$ fertilizer over-inputs in North China and East China caused nutrient imbalances, contributing to acidification, and decreasing C/N ratios (Darilek et al., 2009; Peng, 2011), but also resulting in a reduced yield response to continuously increasing chemical fertilizer use (Huang et al., 2010). As Tian et al. (2012) suggested, the continuous rise in $\mathrm{N}$ fertilization rate might not stimulate $\mathrm{C}$ accumulation in agricultural soils further because crop productivity in response to $\mathrm{N}$ addition has begun to decline in large areas of China, resulting in less $\mathrm{C}$ entering into the soil.

\subsection{Relationships between fertilizer use and partial factor productivity}

The index of PFP (fertilizer partial factor productivity), a useful parameter for identifying constraints to improved fertilizer-use efficiency in farmers' fields, includes two components, $\mathrm{GYo} / \mathrm{F}$ and $\Delta \mathrm{GY} / \mathrm{F}$ (or 
AE, agronomic fertilizer-use efficiency). The terms included are related to the availability of indigenous soil nutrient supply and fertilizer applied, respectively (Cassman et al., 1996). Quantification of the contributions of these two components to PFP provides a more complete understanding of long-term productivity trends and fertilizer-use efficiency (Olk et al., 1999). Cassman et al. (1996) suggested that PFP can be increased by increasing the amount, uptake and utilization of indigenous nutrients, and by increasing the efficiency with which applied nutrients are taken up by the crop and utilized to produce grain. High yields and high PFP in the regions result from a combination of fertile soils, favorable climate, and improved crop and soil management practices, including fertilizer management (Dobermann, 2005).

The statistical data analysis for 1992-2012 showed that the weighted average PFP (in $\mathrm{kg} \mathrm{kg}^{-1}$ ) followed the order (such as in 2012) NE (24.8) > SW (22.7) > NC (17.3) > EC (16.2) > CC (14.9) (Table 3), where the $\mathrm{GYo} / \mathrm{F}$ component (in $\mathrm{kg} \mathrm{kg}^{-1}$ ) of $\mathrm{NE}$ (15.0), SW (23.5), NC (15.5), EC (10.0) and CC (13.4) accounted for about $61 \%, 103 \%, 89 \%, 61 \%$, and $90 \%$ of PFP, respectively, as compared to the $\mathrm{AE}$ component (in $\mathrm{kg} \mathrm{kg}^{-1}$ ) of NE (9.7), SW (-0.8), NC (1.8), EC (6.3), and $\mathrm{CC}$ (1.5). This showed that the GYo/F component accounted for most of PFP, reflecting a higher indigenous soil nutrient supply contribution to yields compared to AE. Results showed that PFP was negatively related to fertilizer use for the five regions, but positively to GYo for NE, EC, and CC but not for NC and SW (Figure 5). This suggests that higher GYo due to indigenous soil fertility may not result in high PFP, while high PFP may be attributed to the balance between indigenous soil nutrient supply and fertilizer applied, rather than fertilizer over-use and resulting excessive soil fertility.

The GYo (in $\mathrm{kg} \mathrm{ha}^{-1}$ ) followed the order SW (6006) $>\mathrm{CC}(5506)>\mathrm{NC} \mathrm{(5004)} \mathrm{>} \mathrm{NE} \mathrm{(4026)} \mathrm{>} \mathrm{EC} \mathrm{(3781)}$ during the period 1992-2012 (Table 3). Over the same period, the average fertilizer increase rates (in $\mathrm{kg} \mathrm{ha}^{-1}$ year $^{-1}$ ) were in the order of $\mathrm{CC}(6.6)>\mathrm{NC}(4.8)>\mathrm{EC}$ (2.4) $>\mathrm{SW}$ (2.1) > NE (1.3) (Figure 3), while yield responses to fertilizer rates (with regression model coefficients, in $\mathrm{kg} \mathrm{kg}^{-1}$ ) were in the order: SW (-0.9) $<\mathrm{CC}(1.1)<\mathrm{NC}(1.7)<\mathrm{EC}(5.7)<\mathrm{NE}$ (9.3) (Table 2). The values of $\mathrm{AE}$ (in $\mathrm{kg} \mathrm{kg}^{-1}$ ), one of two components of PFP (in 2012) were SW $(-0.8)<\mathrm{CC}(1.5)<$ $\mathrm{NC}(1.8)<\mathrm{EC}(6.3)<\mathrm{NE}(9.7)$, similar to the model coefficients of yield responses to fertilizer, showing higher yield responses to fertilizer use for NE and EC than for other regions.

A study in China showed that the indigenous nutrient supply was much higher than previously determined, indicating that over-application of fertilizers in many regions of China had increased both residual nutrients and the potential for losses into the environment (Chuan et al., 2013). Fan et al. (2013) observed that higher yields in control plots led to a higher relative contribution of inherent soil productivity to the total production. A high indigenous nutrient supply in relatively high fertility soils generally resulted in high relative yield (GYo/GYf) but low yield response to fertilization and low agronomic fertilizeruse efficiency (AE) (Chuan et al., 2013). In contrast, a low indigenous nutrient supply in relatively low fertility soils could result in low relative yield but relatively high yield response to fertilizer application and high AE (Zeng et al., 2012). In other words, high inherent soil productivity may lead to low yield response to fertilizer application and low fertilizer-use efficiency, unless fertilizer application rate is adjusted to account for soil nutrient supply. As for $\mathrm{N}$ fertilizer management, Khan et al. (2007) suggested that fertilization beyond crop requirements could be reduced substantially by a shift from the current yield-based $\mathrm{N}$ management that is advocated for short-term economic gain, to soil-based $\mathrm{N}$ management, ideally 
implemented on a site-specific basis by assessment of soil $\mathrm{N}$ availability. Roberts (2008) suggested that though perspectives vary, agronomic nutrient use efficiency is the basis for economic and environmental efficiency, while there must be a balance between optimal nutrient use efficiency and optimal crop productivity. As agronomic efficiency improves, economic and environmental efficiency will also benefit.

\subsection{Some uncertainties in analyzing regional yield differences and fertilizer-use efficiencies}

As some reported, regional crop yield responses to fertilization can vary from year to year due to variation in weather conditions, but also because of indigenous nutrient supply, and interactions of climate variability and nutrient management (Trnka et al., 2012). High yields and high PFPs usually result from a combination of fertile soils, favorable climate, and improved soil nutrient management practices (Dobermann, 2005). However, because climate is the major uncontrollable factor that influences crop yield, it is difficult, but necessary to separate the effect of changes in climate over time from other yield drivers such as the increased use of modern inputs and intensified crop management (Gu, 2003), but also soil quality, genetics, and land management (Licker et al., 2010), to help in developing region-specific fertilizer management practices to reach an optimal, and sustainable level (Darilek et al., 2009) under varying regional climate conditions.

In our study, the statistical models only considered some limited yield-influencing factors, such as fertilizer use, annual climate variability in AR and AMT, and year-time variable, which may cause some uncertainties in analyzing regional yield differences and fertilizer-use efficiencies. However, regional yield or fertilizer efficiency improvement may be also influenced by some other factors, such as increased soil fertility or water availability (Trnka et al., 2012) related to improved farming practices, including use of modern crop varieties, alternative tillage measures, supplemented irrigation, added organic manure, and crop straw or adjusted NPK nutrient input ratios (Zundel and Kilcher, 2007; Darilek et al., 2009; Huang et al., 2010; Licker et al., 2010; Lu et al., 2010; Mahmood et al., 2017; Zhang et al., 2017). Regional grain production was also affected by the changes in regional crop sown areas and crop structures (Figure 2), for instance, the changes in crop structures or crop types between south (more rice) and north regions (more wheat and maize) may cause differences in regional yields and fertilizer-use efficiencies, due to crop nutrient requirements, fertilizer use intensities, and fertilizer-use efficiencies between $\mathrm{C} 4$ crops (maize) and $\mathrm{C} 3$ crops (rice and wheat). Therefore, the regional yield data analysis with statistical models still need to have local farm surveyed data or field experiment data to calibrate to help reduce some uncertainties in evaluating regional yield differences or fertilizer-use efficiencies.

\section{Conclusions}

The agronomic fertilizer-use efficiencies $(\mathrm{AE}$, in $\mathrm{kg}$ $\left.\mathrm{kg}^{-1}\right)$ were in the order: SW $(-0.8)<\mathrm{CC}(1.5)<\mathrm{NC}$ $(1.8)<\mathrm{EC}(6.3)<\mathrm{NE}(9.7)$, showing higher yield responses to fertilizer use for NE and EC than for other regions. There were higher yield responses to soilbased productivity (or inherent soil productivity) for $\mathrm{NC}, \mathrm{CC}$, and SW, or to annual climate variability for $\mathrm{CC}$ than for other regions. The PFP (fertilizer partial factor productivity) analysis suggested that the relative contribution of indigenous soil nutrient supply to productivity (GYo/F component) was higher than the productivity attributed to fertilizer application $\Delta \mathrm{GY} / \mathrm{F}$ or AE component. Therefore, increasing PFP depends on modifying fertilizer rates based on indigenous soil 
nutrient supply to avoid fertilizer over-use and the resulting excessive soil fertility, by adjusting nutrient inputs to more closely match crop demands, and thus improve AE.

In our study, the statistical models only considering some limited yield-influencing factors, such as fertilizer use, climate variability in annual rainfall and annual mean temperature, and the year-time variable. However, regional yield or fertilizer efficiency improvement may be also influenced by some other factors. Further studies in evaluating regional yield differences or fertilizer-use efficiencies still need to have local farm surveyed data or field experiment data for calibration to reduce some uncertainties.

\section{Acknowledgements}

The studies are part of The National Basic Research Program (“973 Program”, no. 2011CB100501) financed by the Ministry of Science and Technology of China.

\section{References}

Brady, N.C. 1974. The nature and properties of soils. MacMillan Publishing Co., Inc. New York.

Cassman, K.G., Gines, G.C., Dizon, M.A., Samson, M.I., Alcantar, J.M. 1996. Nitrogen use efficiency in tropical lowland rice systems: contribution from indigenous and applied nitrogen. Field Crop. Res. 47, 1-12.

Chuan, L.M., He, P., Pampolino, M.F., Johnston, A.M., Jin, J.Y., Xu, X.P., Zhao, S.C., Qiu, S.J., Zhou, W. 2013. Establishing a scientific basis for fertilizer recommendations for wheat in China: Yield response and agronomic efficiency. Field Crop. Res. 140, 1-8.

Darilek, J.L., Huang, B., Wang, Z.G., Qi, Y.B., Zhao, Y.C., Sun, W.X., Gu, Z.Q., Shi, X.Z. 2009. Changes in soil fertility parameters and the envi- ronmental effects in a rapidly developing region of China. Agric. Ecosyst. Environ. 129, 286-292.

Dobermann, A.R. 2005. Nitrogen use efficiency: state of the art. Agronomy \& Horticulture: Faculty Publications. Paper 316. http://digitalcommons. unl.edu/agronomyfacpub/316.

Duan, X.W., Yun, X., Feng, Y.J., Yin, S.Q. 2009. Study on the method of soil productivity assessment in black soil region of Northeast China. Agric. Sci. in China 8, 472-481.

Fan, M.S., Lal, R., Cao, J., Qiao, L., Su, Y.S., Jiang, R.F., Zhang, F.S. 2013. Plant-based assessment of inherent soil productivity and contributions to China's cereal crop yield increase since 1980 . PLoS ONE. 8, e74617.

Gu, L. 2003. Comment on "Climate and management contributions to recent trends in U.S. agricultural yields". Science. 300, 1505.

Huang, S., Zhang, W.J., Yu, X.C., Huang, Q.R. 2010. Effects of long-term fertilization on corn productivity and its sustainability in an Ultisol of southern China. Agric. Ecosyst. Environ. 138, 44-50.

ISS-CAS, Institute of Soil Science, Chinese Academy of Science (ISS-CAS). 2003. Scientific data base. China Soil data base, http://www.soil.csdb.cn/ Last Updated: March, 2003. Institute of Soil Science, CAS, China.

Khan, S.A., Mulvaney, R.L., Ellsworth, T.R., Boast, C.W. 2007. The myth of nitrogen fertilization for soil carbon sequestration. J. Environ. Qual. 36, 1821-1832.

Licker, R., Johnston, M., Foley, J.A., Barford, C., Kucharik, C.J., Monfreda, C., Ramankutty, N. 2010. Mind the gap: how do climate and agricultural management explain the 'yield gap' of croplands around the world? Glob. Ecol. Bioge. 19, 769-782.

Liu, J.G., Diamond, J. 2005. China's environment in a globalizing world. Nature. 435, 1179-1186. 
Liu, Z., Li, B.G., Fu, J. 2009. Nitrogen balance in agro-ecosystem in China from 1978 to 2005 based on DSS. Transactions of the Chinese Soc. Agric. Engineer. 25, 168-175.

Lu, C.Y., Ma, J., Chen, X., Zhang, X.D., Shi, Y., Huang, B. 2010. Effect of nitrogen fertilizer and maize straw incorporation on $\mathrm{NH}_{4}^{+}{ }^{+15} \mathrm{~N}$ and $\mathrm{NO}_{3}{ }^{-}-$ ${ }^{15} \mathrm{~N}$ accumulation in black soil of Northeast China among three consecutive cropping cycles. J. Soil Sci. Plant Nutr. 10, 443-453.

Mahmood, F., Khan, I., Ashraf, U., Shahzad, T., Hussain, S., Shahid, M., Abid, M., Ullah, S. 2017. Effects of organic and inorganic manures on maize and their residual impact on soil physico-chemical properties. J. Soil Sci. Plant Nutr. 17, 22-32.

NBSC (National Bureau of Statistics of China). 19932013. China statistical yearbook-1993-2013. Beijing: China Statistics Press, 1993-2013.

NDRC (The National Development and Reform Commission). 1993-2013. National farm product cost-benefit survey-1993-2013. China Statistics Press, 1993-2013.

Novoa, R., Loomis, R.S., 1981. Nitrogen and plant production. Plant Soil. 58, 177-204.

Olk, D.C., Cassman, K.G., Simbahan, G., Sta Cruz, P.C.S., Abdulrachman, S., Nagarajan, R., Tan, P.S., Satawathananont, S. 1999. Interpreting fertilizer-use efficiency in relation to soil nutrientsupplying capacity, factor productivity, and agronomic efficiency. Nutr. Cycl. Agroecosyst. 53, $35-41$.

Peng, K. 2011. Changes of soil carbon and nitrogen storages under modern industrialization in a rural landscape of North China Plain. Proc. Environ. Sci. 8, 81-89.

Pierce, F.J., Larson, W.E., Dowdy, R.H., Graham, W.A.P. 1983. Productivity of soil: Assessing of long-term changes due to erosion. J. Soil Water Conser. 38, 39-44.

Roberts, T.L. 2008. Improving nutrient use efficiency. Turkish J. Agric. Forest. 32, 177-182.

Roy, R.N., Finck, A., Blair, G.J., Tandon, H.L.S. 2006. Plant nutrition for food security, a guide for integrated nutrient management, FAO Fertilizer and Plant Nutrition Bulletin 16, FAO, RomeItaly. Chapter 4. Soil fertility and crop production. 43-90, Rome, 2006.

SAS Institute Inc. 2004. SAS1 9.1.2 Qualification Tools User's Guide. SAS Institute Inc, Cary, NC.

Shen, R.P., Sun, B., Zhao, Q.G. 2005. Spatial and temporal variability of $\mathrm{N}, \mathrm{P}$ and $\mathrm{K}$ balances for agroecosystems in China. Pedosphere. 15, 347355.

Shi, Q.H., Wang, H., Chen, F., Chu, Q.Q. 2010. The spatial-temporal distribution characteristics and yield potential of medium-low yielded farmland in China. Chinese Agric. Sci. Bull. 26, 369-373.

Sun, W.J., Huang, Y., Zhang, W., Yu, Y.Q. 2010. Carbon sequestration and its potential in agricultural soils of China. Glob. Biogeochem. Cycl. 24, GB3001.

Tian, H.Q., Lu, C.Q., Melillo, J., Ren, W., Huang, Y., Xu, X.F., Liu, M.L., Zhang, C., Chen, G.S., Pan, S.F., Liu, J.Y., Reilly, J. 2012. Food benefit and climate warming potential of nitrogen fertilizer uses in China. Environ. Res. Lett. 7, 044020.

Trnka, M., Brazdil, R., Olesen, J.E., Eitzinger, J., Zahradnicek, P., Kocmankova, E., Dobrovolny, P., Stepanek, P., Mozny, M., Bartosova, L., Hlavinka, P., Semeradova, D., Valasek, H., Havlicek, M., Horakova, V., Fischer, M., Zalud, Z. 2012. Could the changes in regional crop yields be a pointer of climatic change? Agric. Forest Meteor. 166-167, 62-71.

Xin, L.J., Li, X.B., Tan, M.H. 2012. Temporal and regional variations of China's fertilizer consump- 
Zhang, H.Q., Yu, X.Y., Jin, Z.Y., Zheng, W., Zhai, B.N., Li, Z.Y. 2017. Improving grain yield and water use efficiency of winter wheat through a combination of manure and chemical nitrogen fertilizer on the Loess plateau, China. J. Soil Sci. Plant Nutr. 17, 461-474.

Zeng, X.M., Han, B.J., Xu, F.S., Huang, J.L., Cai, H.M., Shi, L. 2012. Effect of optimized fertilization on grain yield of rice and nitrogen use efficiency in paddy fields with different basic soil fertilities. Sci. Agric. Sinica. 45, 2886-2894. tion by crops during 1998-2008. J. Geogra. Sci. 22, 643-652.

Zhou, J.M. 2013. Protection of arable land resources and increase of soil productivity in China. Bull. Chinese Acad. Sci. 28, 269-274. (in Chinese).

Zundel, C., Kilcher, L. 2007. Organic agriculture and food availability. Issue paper. International Conference on Organic Agriculture and Food Security. 3-5 May. Rome, Italy. 